\title{
THE USE OF ALLOY 718 IN THE SPACE SHUTTLE MAIN ENGINE
}

\author{
R. P. Jewett \& J. A. Halchak
}

Rocketdyne, A Division of Rockwell Int.

6633 Canoga Avenue

Canoga Park, CA 91303

\begin{abstract}
$\underline{\text { Abstract }}$
Alloy 718 comprises $51 \%$ of the total weight of the Space Shuttle Main Engine. It is used for more than 1,500 individual parts in hydrogen, oxygen, and hydrogen-rich steam at temperatures ranging from $-253^{\circ} \mathrm{C}$ to $760^{\circ} \mathrm{C}$. The severe operating conditions of the SSME Iead to potential problems such as hydrogen-environment embrittlement and oxygen ignition. This paper will discuss how these potential problems are controlled through design, protective barriers, and heat treatment. Operational experiences, fabrication techniques, and welding microfissures will also be discussed.
\end{abstract}




\section{Introduction}

The Space Shuttle Main Engine (SSME) is a liquid hydrogen-oxygen staged combustion engine which develops a thrust of $2,114 \mathrm{kN}$. The severe operating conditions of hydrogen environment, rapid start and stop temperature transients, and high temperatures and pressures offer a unique set of material challenges not found in any other current materials applications. In addition, weight limitations are always a consideration where fabricating vehicles for earth orbit. An engine or vehicle weight of $1 \mathrm{~kg}$ imposes a corresponding $30 \mathrm{~kg}$ reduction in payload.

\section{Space Shuttle Main Engine}

When the SSME was designed in the early 1970s, the choice of structural materials was limited for applications requiring useful strength at temperatures as high as $760^{\circ} \mathrm{C}$ and room temperature strengths of at least 1,400 MPa. Figures 1,2, and 3 show the mechanical property vs temperature data available at that time and show clearly the advantages of alloy 718 over other available materials from both a strength and ductility point of view. Other considerations for selecting alloy 718 were weldability, isotropy, ease of fabrication, and relatively simple heat treating procedures. Alloy 718 comprises $51 \%$ by weight of the SSME and accounts for approximately 1,500 engine components. It undergoes environments of liquid and gaseous hydrogen, liquid oxygen, and hydrogen-rich steam at temperatures ranging from $-253^{\circ} \mathrm{C}$ to $760^{\circ} \mathrm{C}$.

Figure 4 shows the SSME and its major components. All structural components utilize alloy 718 in some form. Figure 5 is an exploded view of the SSME showing the shape of the major components.

\section{Powerhead}

The heart of the SSME is the powerhead. Figure 6 is a cutaway view showing the powerhead components. The powerhead is comprised of the hot gas manifold, main injector, main combustion chamber, fuel and oxygen preburner, and the fuel and oxygen high-pressure turbopumps. All the components make extensive use of alloy 718 as described below.

\section{Hot Gas Manifold}

The hot gas manifold, depicted in Figure 7, serves two purposes: (1) it is the structural backbone of the engine, supporting almost all the engine weight, including the high-pressure turbopumps, the preburners, the main injector, main combustion chamber (MCC), and the nozzle; and (2) it provides the passageways to carry the hydrogen-rich combustion products into the MCC after passing through the turbopump turbines. It is produced in two halves, each half a large, closed-die forging, weighing approximately $680 \mathrm{~kg}$. After

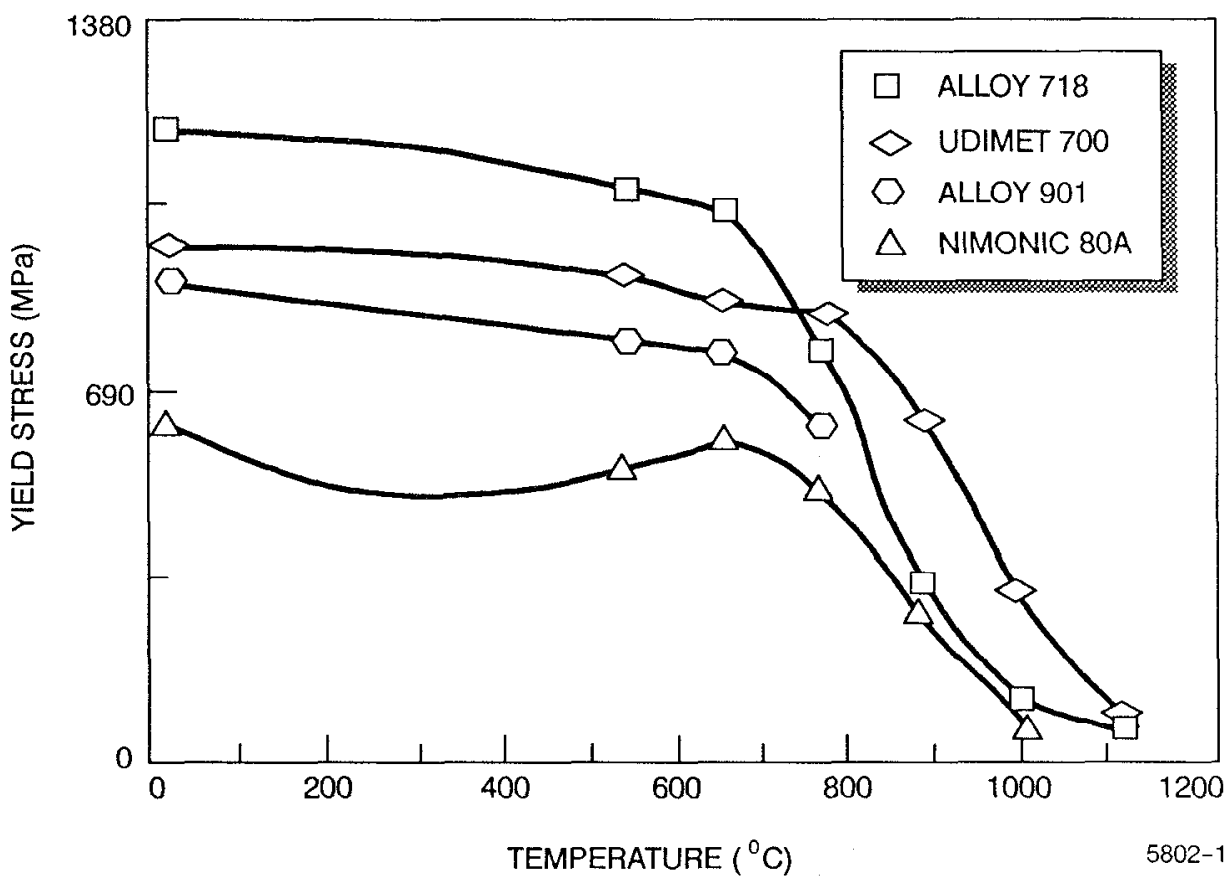

Figure 1. Yield Strength Comparison for SSME Alloys 


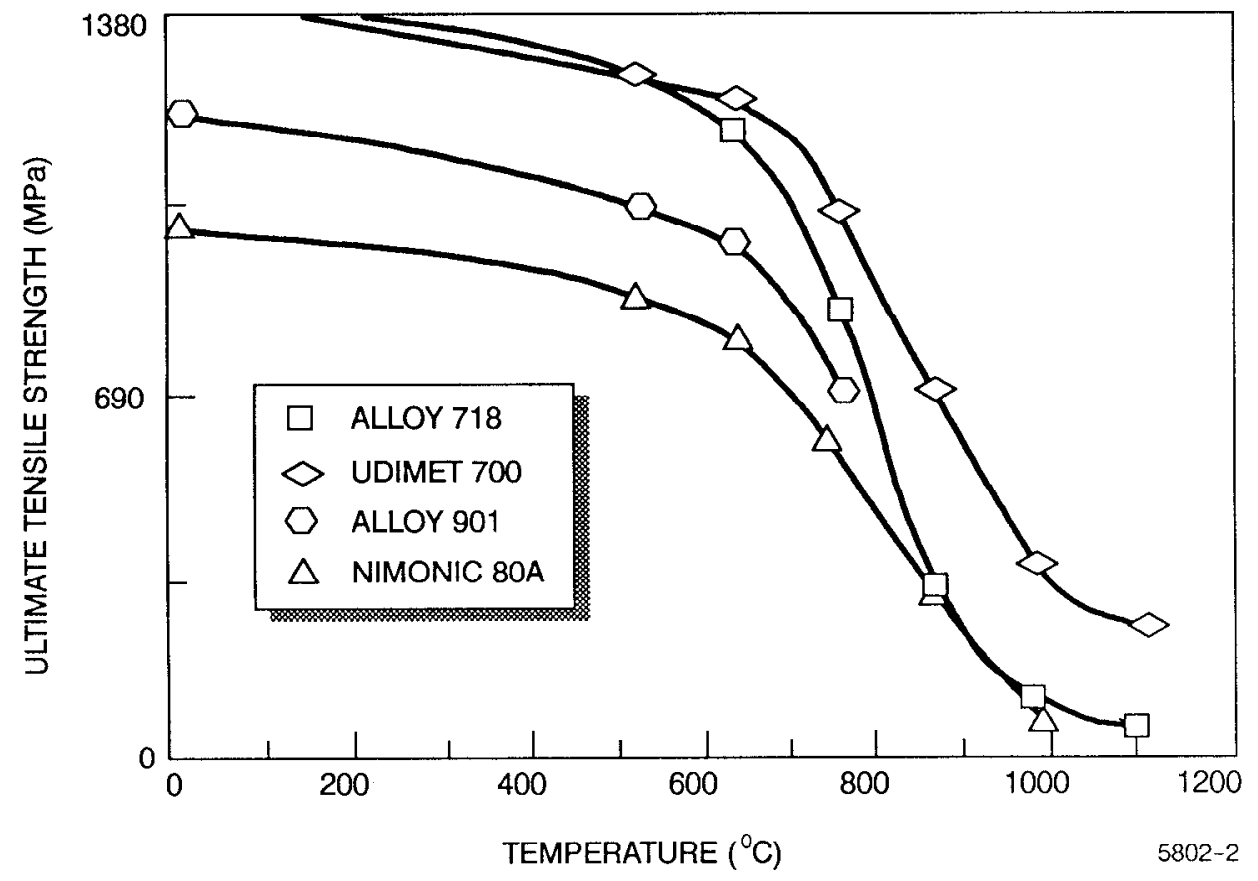

Figure 2. Ultimate Tensile Strength Comparison for SSME Alloys

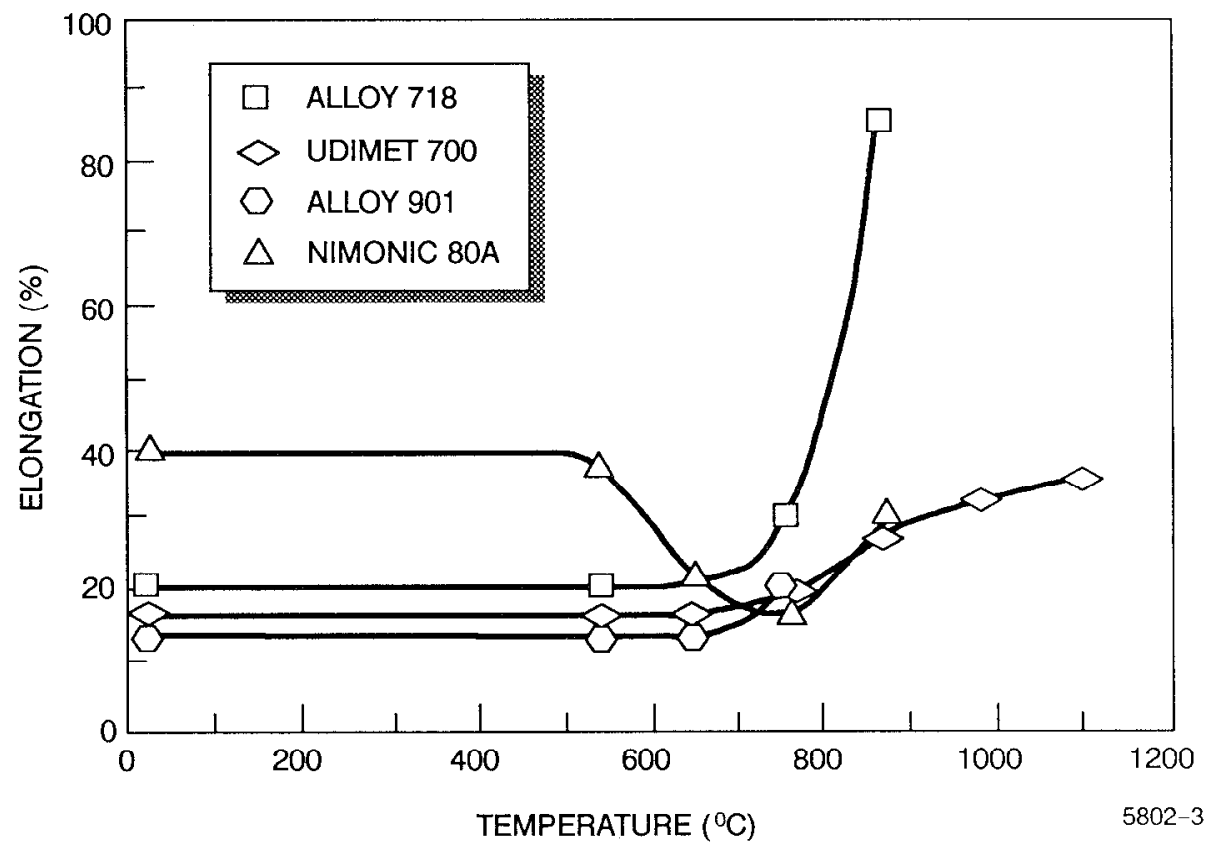

Figure 3. Ductility Comparison for SSME Alloys 


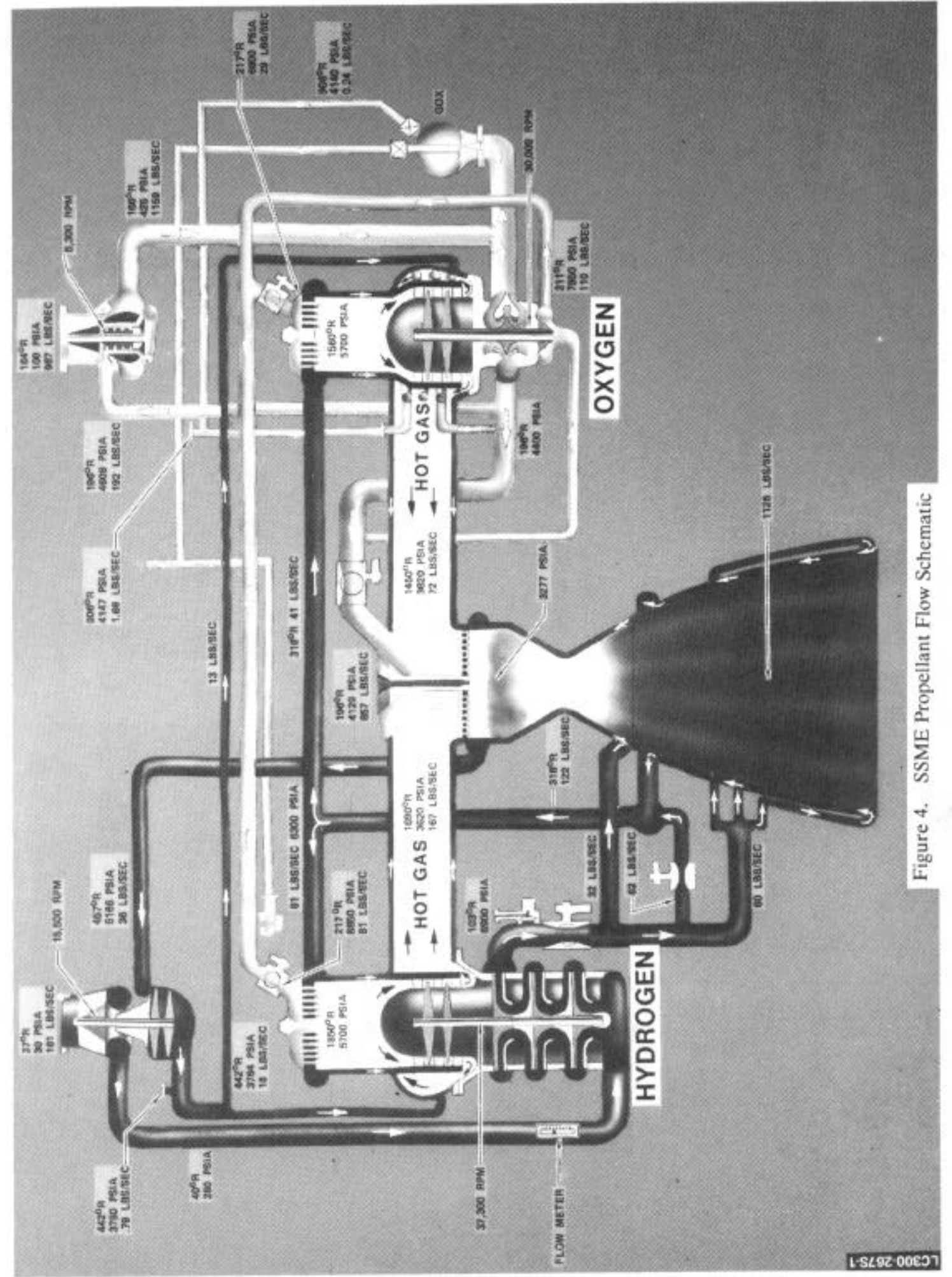




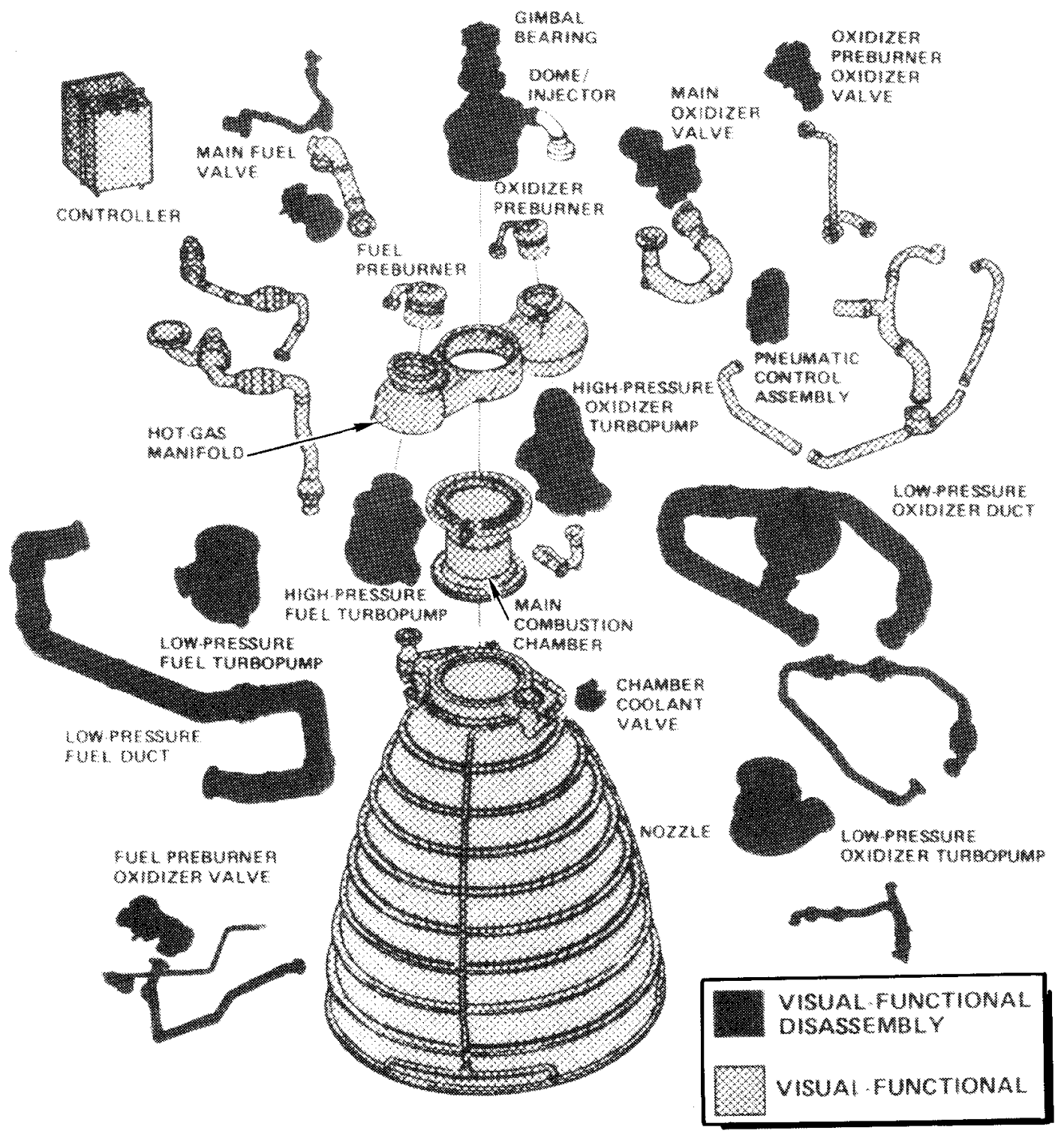

$5802-5$

Figure 5. SSME Major Components 


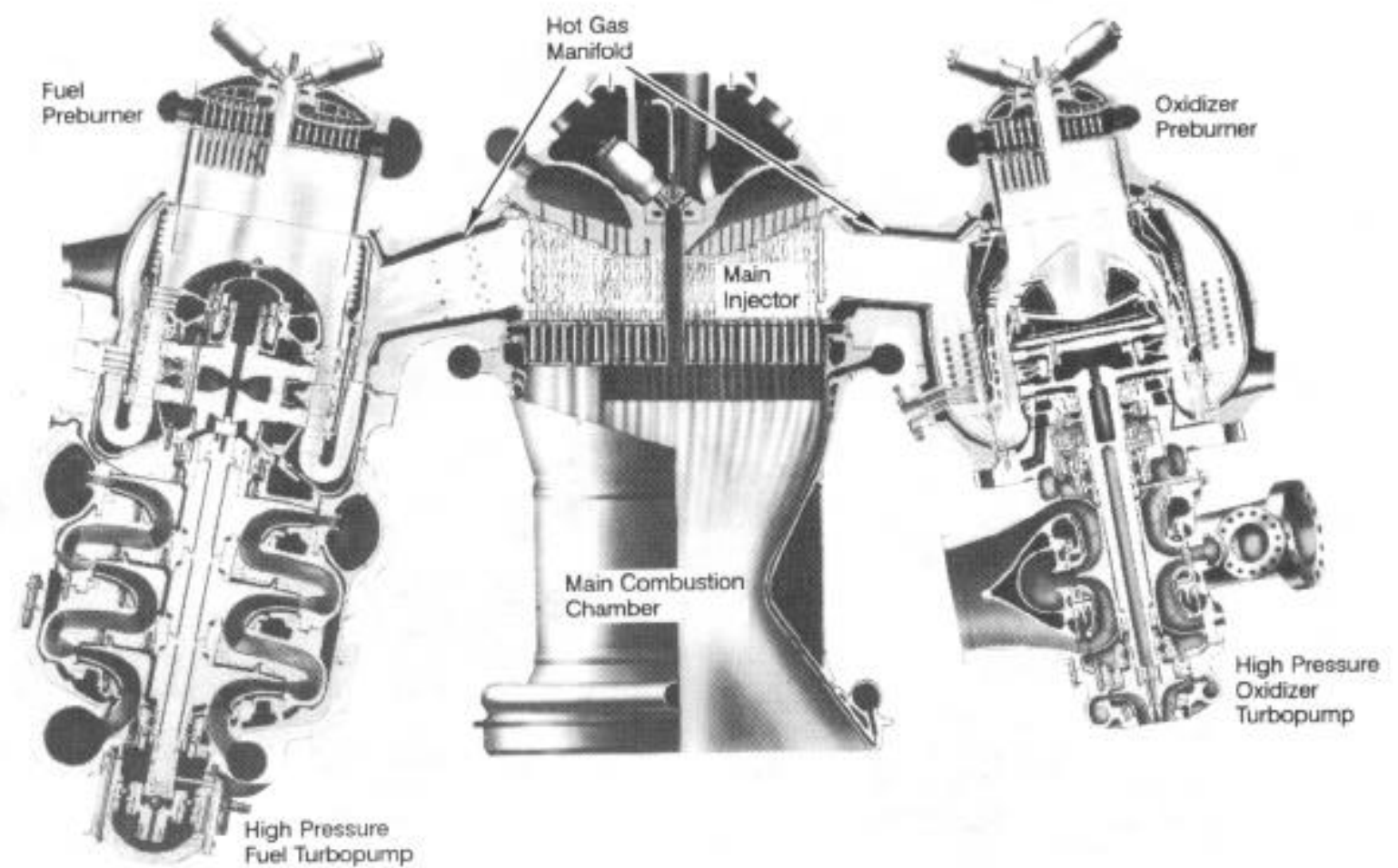

$5802-13$

Figure 6. SSME Powerhead Component Arrangement

machining and heat treatment, the halves are joined by electron-beam (EB) welding in a butt-type joint configuration which ranges in thickness up to $31.75 \mathrm{~mm}$. An integral self-aligning backup strip is employed at the root of this EB weldment. After welding, this backup is removed by machining to provide a smooth, defect-free weld root configuration. In operation, the manifold is subjected to an internal pressure of $24.8 \mathrm{MPa}$ from hydrogen-rich steam at $760^{\circ} \mathrm{C}$. The structural outer walls of the manifold are insulated with an alloy 903 sheet metal liner, with the space between the liner and wall cooled by hydrogen gas to reduce the outer wall temperature to a maximum of $180^{\circ} \mathrm{C}$.

\section{Preburners}

The SSME uses two preburners (Figure 6), each of which combusts hydrogen and oxygen in an extremely fuel-rich mixture ratio, for dual purposes: (1) to provide high-pressure hot gases to drive the fuel and oxidizer turbopump turbines and (2) to increase combustion efficiency by preheating the hydrogen fuel before it is injected into the MCC. The structural body and inlet manifold of each preburner are machined from alloy 718 forgings and from preformed sheet. The forgings and the sheet are joined by EB and gas tungsten arc (GTA) welding.

\section{High-Pressure Oxidizer Turbopump}

The function of the high-pressure oxidizer turbopump (HPOTP) is to provide a high-pressure, high-volume flow of liquid oxygen to the main injector arid to the preburner injectors sufficient to ensure positive injection of oxidizer at all thrust levels (Figure 8). The HPOTP is a centrifugal pump consisting of a double-entry main impeller and a smaller, single-entry boost impeller on a common drive shaft and develops $16.4 \times 10^{6} \mathrm{~W}$ at $29,000 \mathrm{rpm}$. The low-pressure oxidizer pump delivers liquid oxygen to the HPOTP main impeller at about $2.9 \mathrm{MPa}$. The main impeller increases this pressure to almost $35 \mathrm{MPa}$ and most of this flow is directed to the MCC injector. A small portion of this liquid oxygen flow is diverted to the boost impeller which increases the pressure to approximately $55 \mathrm{MPa}$ to feed the preburners. The main impeller is machined from an alloy 718 closed-die forging and the boost impeller is an alloy 718 precision investment casting. The pump housing, also alloy 718, is a complex welded assembly composed of castings, forgings, and formed sheet. All components are in the solution-treated and aged condition subsequent to welding. Alloy 718 was selected for its high strength, compatibility with liquid oxygen, and good toughness at the operating temperature of $-179^{\circ} \mathrm{C}$ (Ref. 1). 


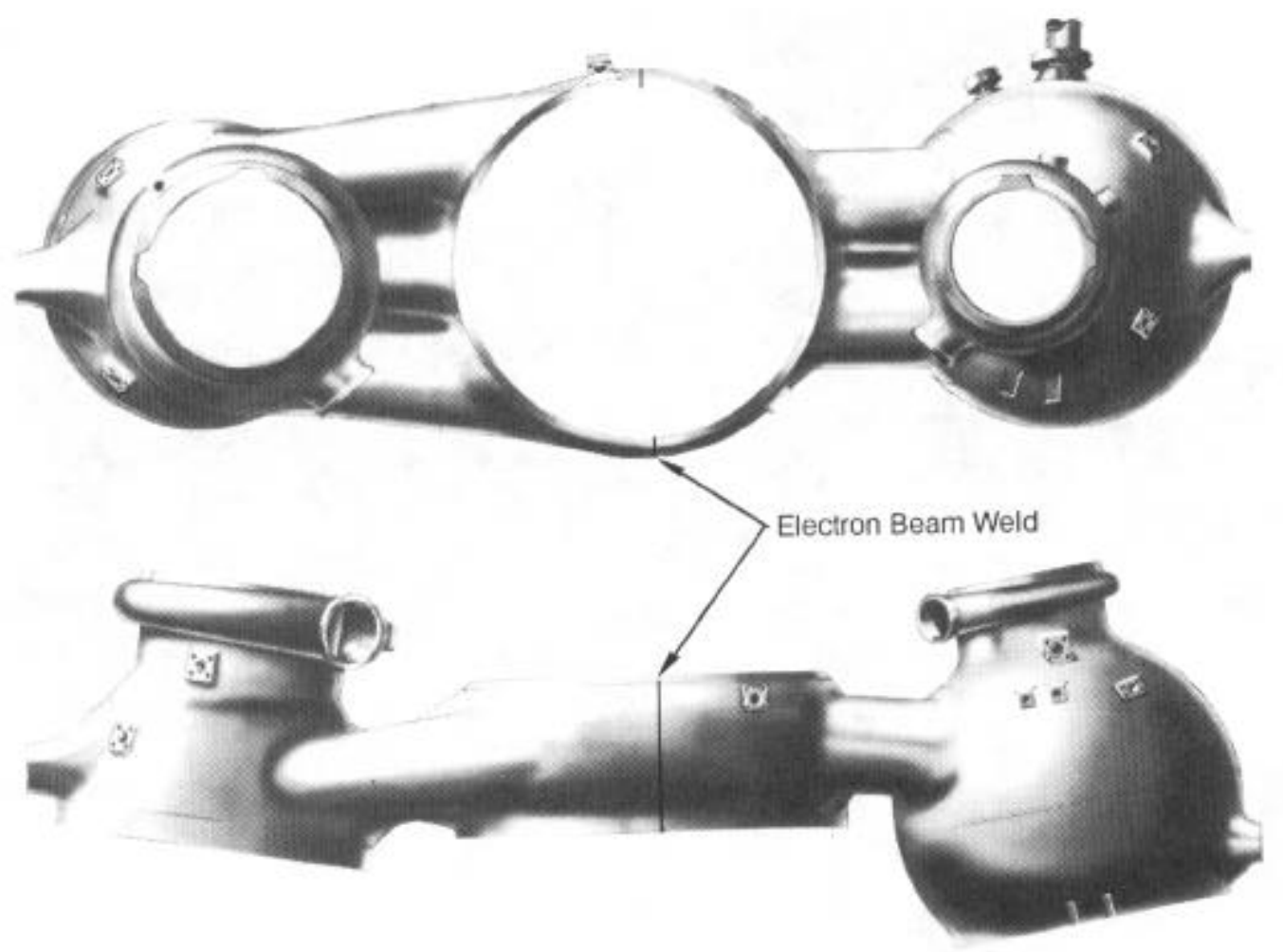

$5802-7$

Figure 7. SSME Hot-Gas Manifold

(Entire Outer Shell is Alloy 718)

\section{High-Pressure Fucl Turbopump}

The high-pressure fuel turbopump (HPFTP) provides a high-pressure, high-volume flow of liquid hydrogen fuel to the preburner injectors, the MCC, the nozzle, and other cooling circuits of the engine (Figure 9). All this fuel eventually reaches the main injector where the combustion process is completed. The HPFTP is a three-stage centrifugal pump that uses two interstage diffusers to pass the hydrogen from one stage to the next.

The pump is driven by a two-stage, hot-gas turbine at rotational speeds up to $37,000 \mathrm{rpm}$ and develops a maximum of $57.4 \times 10^{6} \mathrm{~W}$ of power at a discharge pressure is $47.8 \mathrm{MPa}$ and a head of $5,900 \mathrm{~m}$. The three impellers are made from a titanium alloy, but the pump and turbine housing, the discharge volute, and the main pump shaft are alloy 718. As in the oxidizer pump, the housing is a welded assembly of forgings, castings, and preformed sheet metal. In the fuel pump, the thermal differentials which must be accommodated by the alloy 718 housing are particularly severe. At the turbine-to-pump interface, less than $60 \mathrm{~mm}$ separate liquid hydrogen at $-253^{\circ} \mathrm{C}$ from preburner hot-gas combustion products (hydrogen-rich steam) at $840^{\circ} \mathrm{C}$.

\section{Main Injector}

The main injector (Figure 10) injects propellants into the MCC and thoroughly mixes them for efficient combustion. The body of the main injector is electrically discharged machined alloy 718 , which is subsequently chemically milled to remove the recast layer (Ref.1) Six hundred alloy 188 posts are inertia welded to the alloy 718, injector body to form the injector elements. A protective weld overlay of alloy 903 is applied to the weld joint between the injector body and the hot-gas manifold to avoid hydrogen-environment embrittlement (HEE). The oxidizer inlet manifold and the structural elements of the main injector are also made from alloy 718 .

\section{Main Combustion Chamber}

The MCC (Figure 11) contains the combustion process, accelerates the gas flow to throat sonic velocity and initiates the expansion process through the divergent section. The chamber includes a hydrogen-cooled copper alloy liner, an alloy 718 jacket (for structural support) and inlet and outlet coolant manifolds of alloy 718 . The structural jacket is machined from a dic forging as twin halves which are subsequently EB welded around the liner and to the coolant manifolds. The MCC contains combustion gases $24 \mathrm{MPa}$ and $2760^{\circ} \mathrm{C}$. Hydrogen pressure in the coolant inlet manifold is also $24 \mathrm{MPa}$. 


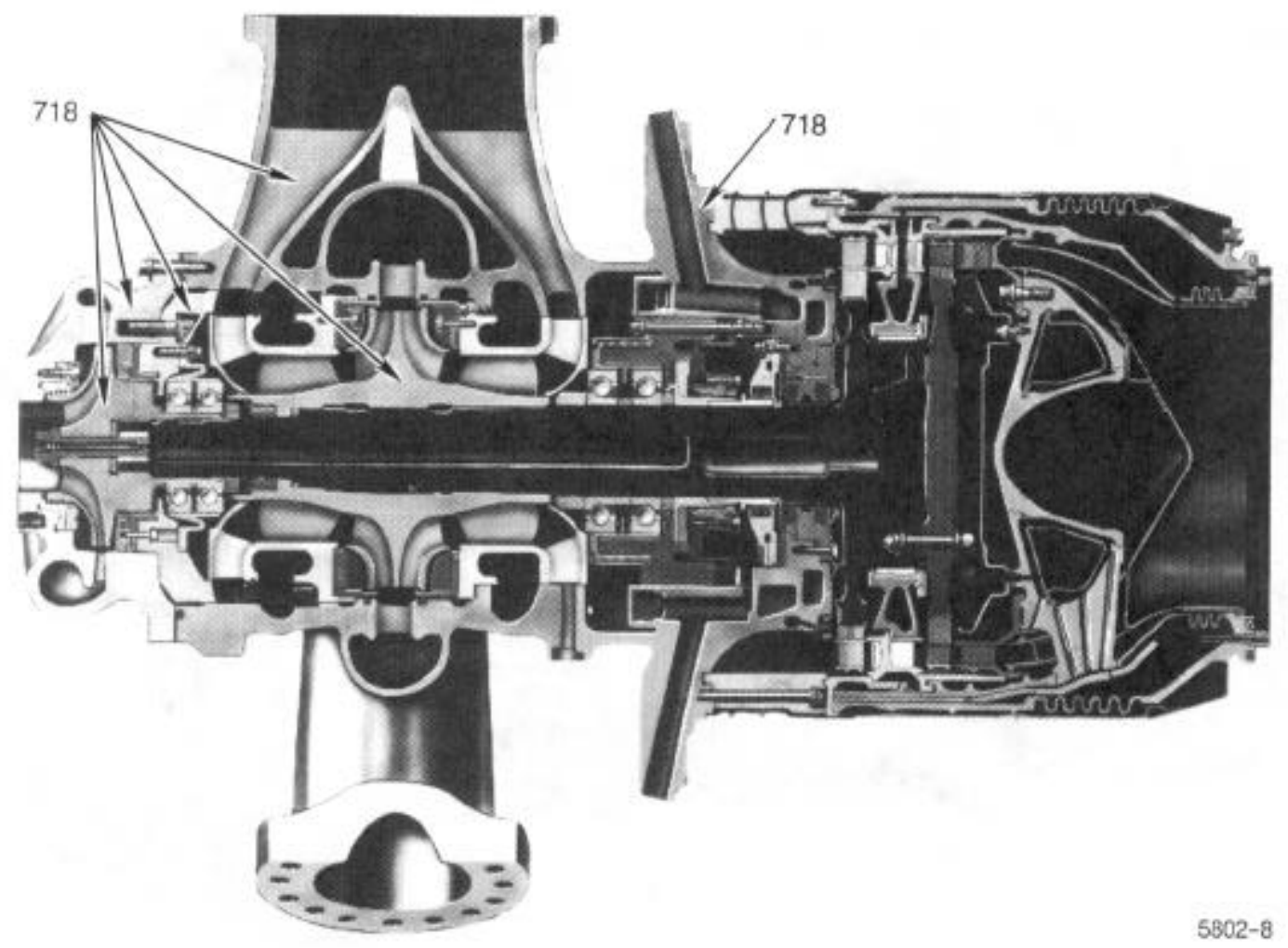

Figure 8. SSME High-Pressure Oxygen Turbopump

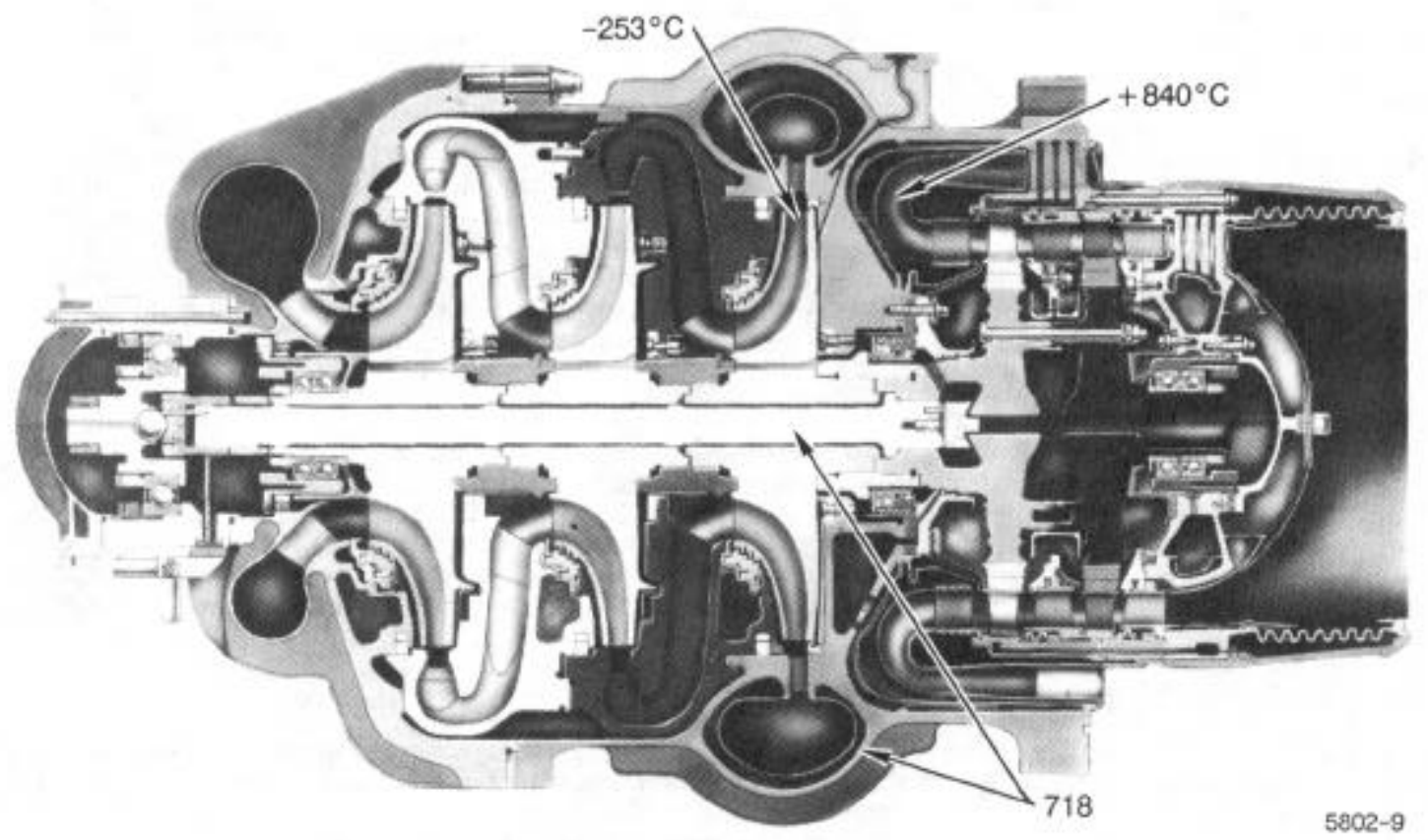

Figure 9. SSME High-Pressure Fuel Turbopump 


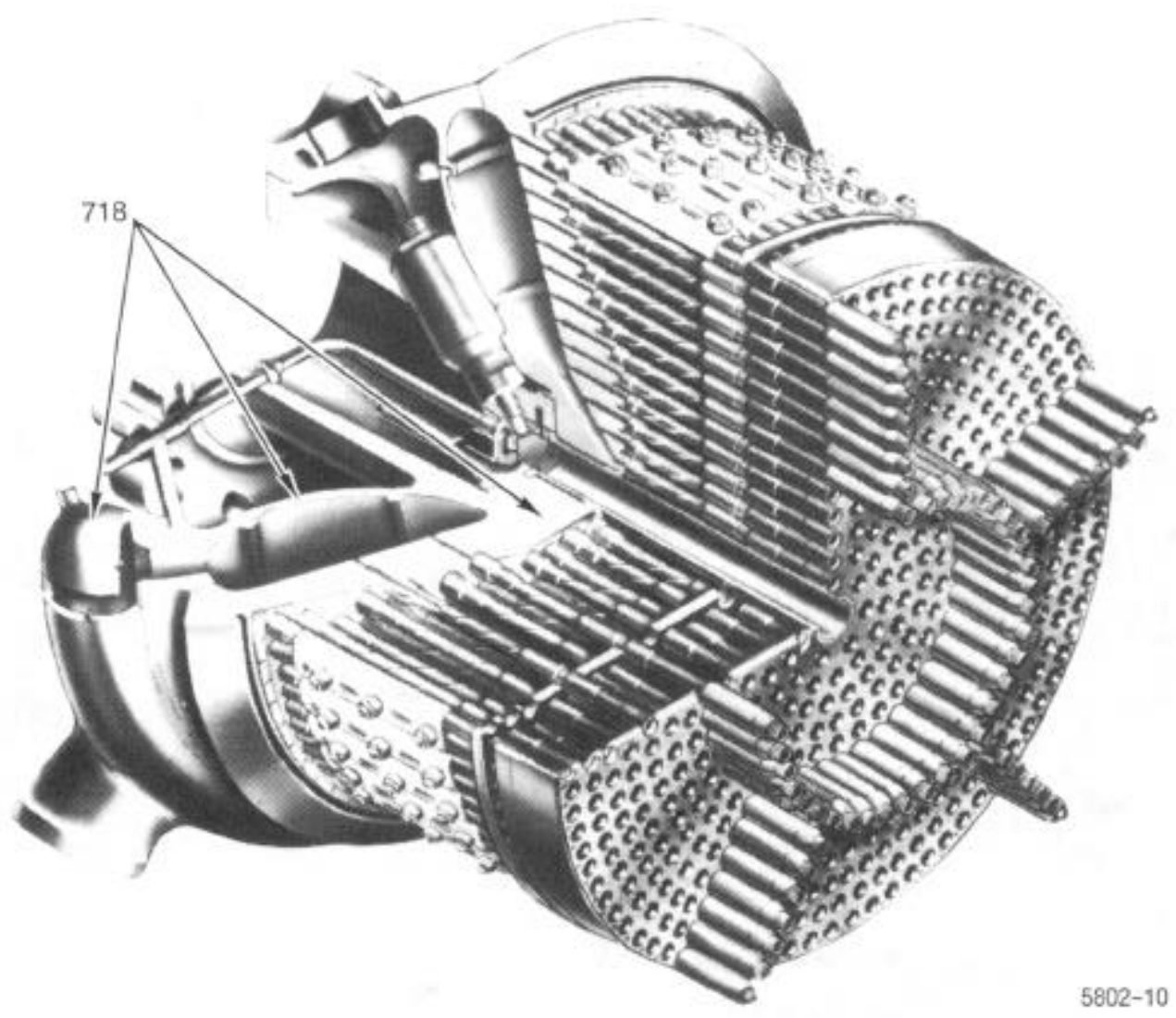

Figure 10. Main Injector Assembly

Nozzle

The nozzle (Figure 12) is of the converging-diverging type whose purpose is to increase the velocity of the exhaust gas stream by controlling its expansion and resultant pressure reduction. The SSME nozzle is regeneratively cooled with hydrogen; it is approximately $370 \mathrm{~cm}$ in diameter at the exit and weighs $423 \mathrm{~kg}$. It consists of 1080 A 286 stainless steel tapered and shaped tubes which are brazed to themselves and to an alloy 718 structural jacket (Ref. 1). Nine hat bands, also alloy 718, are welded around the jacket for hoop strength. Inlet and outlet coolant manifolds are GTA welded to the top and bottom of the nozzle. Three hydrogen transfer ducts feed the inlet manifold. Both manifolds and ducts are made from alloy 718 .

\section{Operational Considerations}

One early concern about the use of alloy 718 was the potential for HEE. The phenomena of HEE and its application to nickel-base alloys was investigated under the Saturn engine programs and several NASA technology programs. In the low-temperature solution-treated condition $\left(954^{\circ} \mathrm{C}\right.$ ), alloy 718 is particularly embrittled; the ratio of notched tensile strength in high-pressure hydrogen to high-pressure helium is 0.59 . Walter et al. (Ref. 2) attributed this to the presence of the orthorhombic $\mathrm{Ni}_{3} \mathrm{Cb}$ (delta) phase present in the microstructure. Solution treating at $1038^{\circ} \mathrm{C}$ eliminated this phase and the notch strength ratio rose to 0.76 . The smooth specimen reduction of area ratio also increased from 0.03 to 0.5 respectively, with acceptable room temperature ductility. These improvements in ductility and toughness made alloy 718 acceptable for use in the SSME. However, since alloy 718 was shown to be somewhat susceptible to HEE, several design philosophies were adopted for use of alloy 718 in hydrogen fuels. One technique utilized was to minimize the strains in components which were exposed to hydrogen in the vicinity of normal room temperature. This was accomplished by proof loading pressurized components prior to exposure or designing pressurized components to have surface strains less than the strain-to-crack initiation strain in hydrogen. Where strains were higher, copper plating was used on components exposed to high-pressure hydrogen at temperatures less than $205^{\circ} \mathrm{C}$. A minimum thickness of $0.1 \mathrm{~mm}$ of copper was required to prevent embrittlement. The use of alloy 903 as a liner and as a weld overlay was also employed to serve as a barrier to prevent hydrogen embrittlement.

In the early period of use, it was thought that alloy 718 and other nickel-base alloys were immune to internal hydrogen embrittlement (IHE). Recent results have shown this is not the case. Table I shows the results of a series of tests for alloy $718\left(1038^{\circ} \mathrm{C}\right.$ solution treat) after thermal charging at $649^{\circ} \mathrm{C}$ for 15 min (Ref. 3). 


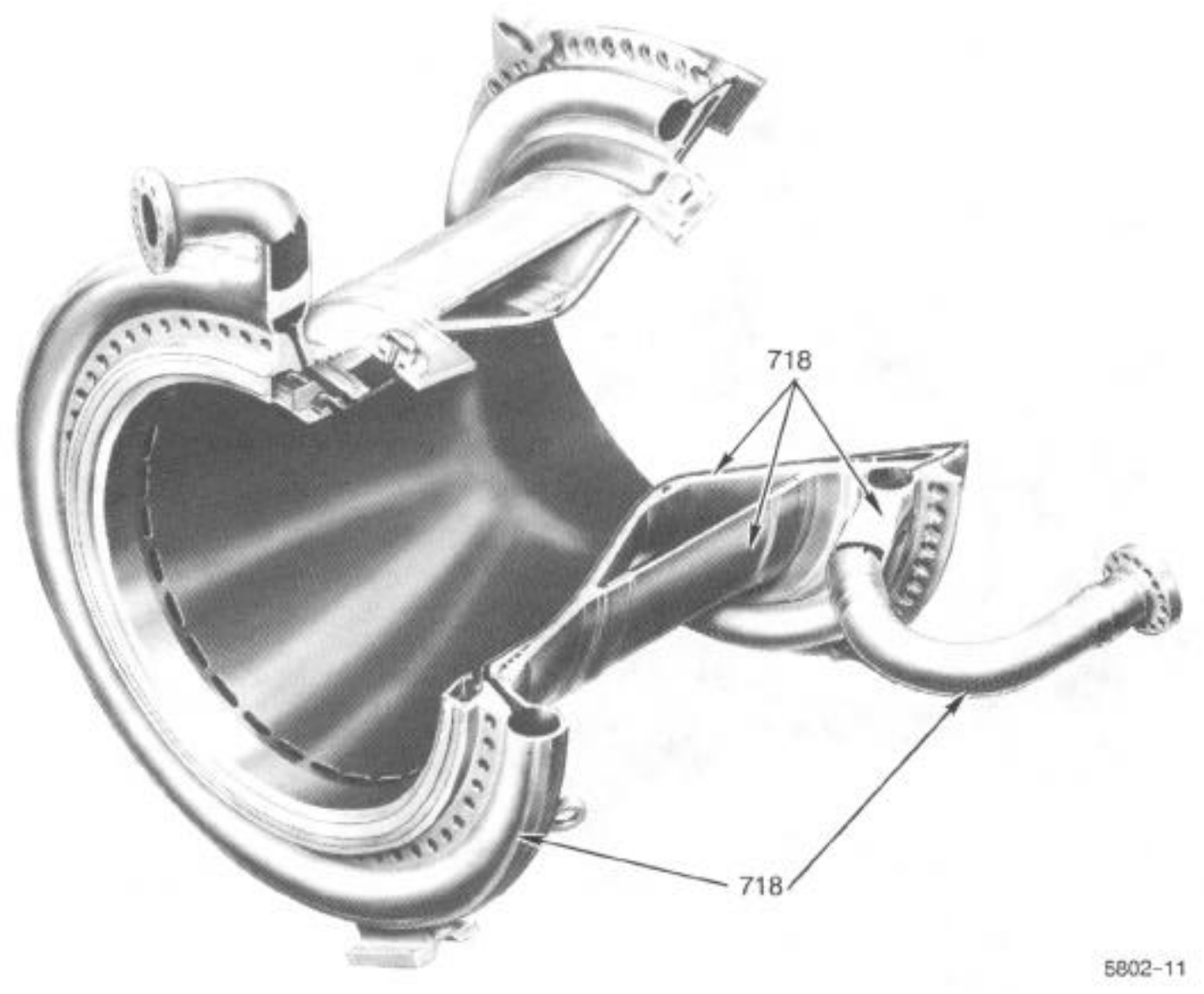

Figure 11. SSME Main Combustion Chamber

Table 1-1. Hydrogen Environment Embrittlement of Hydrogen-Charged Samples. (Samples Tested in $34.9 \mathrm{MPa}$ Hydrogen and Helium)

\begin{tabular}{|c|c|c|c|c|c|}
\hline \multirow{2}{*}{ Test } & \multirow{2}{*}{ Type } & \multicolumn{2}{|c|}{ Helium } & \multicolumn{2}{|c|}{ Hydrogen } \\
\hline & & FTU (MPa) & $\mathrm{RA}(\%)$ & FTU (MPa) & $\mathrm{RA}(\%)$ \\
\hline 1 & Control & 1,427 & 34.4 & 1,406 & 15.1 \\
\hline 2 & $\begin{array}{l}\mathrm{H}_{2} \text { charge } \\
\left(15 \text { min at } 649^{\circ} \mathrm{C}\right)\end{array}$ & 1,427 & 6.9 & 1,372 & 7.8 \\
\hline 3 & $\begin{array}{l}\mathrm{H}_{2} / \mathrm{H}_{2} \mathrm{O} \text { charge } \\
\left(15 \text { min at } 649^{\circ} \mathrm{C}\right)\end{array}$ & 1,337 & 3.7 & 1,334 & 4.7 \\
\hline 4 & $\begin{array}{l}\text { Type } 3 \text { after } 60 \text { days at } \\
\text { ambient temperature }\end{array}$ & 1,331 & 6.1 & 1,372 & 4.1 \\
\hline 5 & $\begin{array}{l}\text { Type } 3 \text { plus vacuum } \\
\text { anneal }\end{array}$ & & & 1,399 & 13.6 \\
\hline 6 & Gold plated & & & 1,455 & 24.7 \\
\hline 7 & Type 6 plus type 2 & & & 1,496 & 16.6 \\
\hline
\end{tabular}




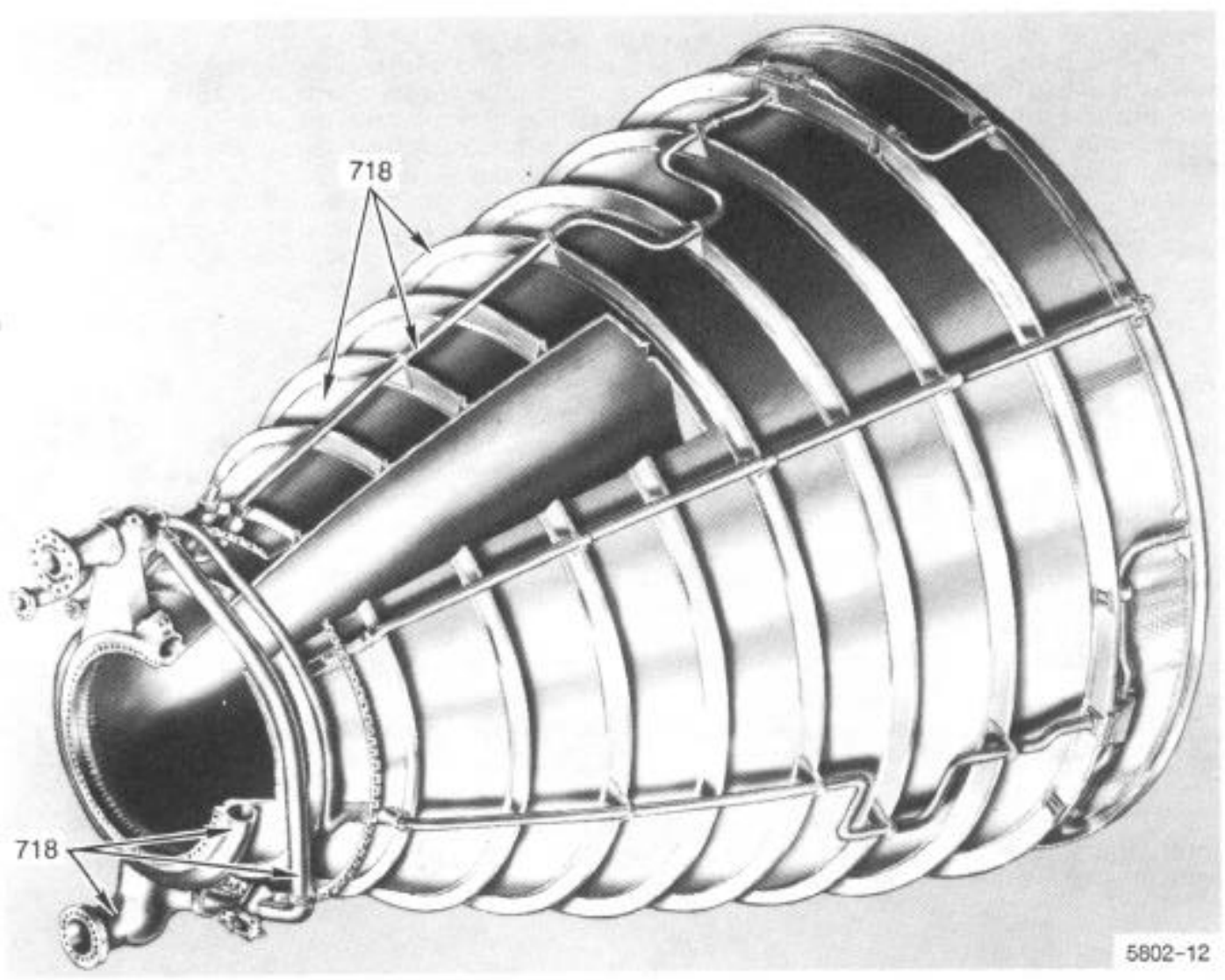

Figure 12. SSME Nozzle Assembly

When uncharged control specimens were tested in hydrogen, a 57\% drop in RA was recorded. Thermally charged specimens, when tested in hydrogen, then exhibited an additional $50 \%$ drop in RA. The use of gold plating to reduce hydrogen effects is shown by tests 6 and 7, when gold-plated specimens are tested in hydrogen, a $30 \%$ loss of RA is observed. Gold plating prior to thermal exposure reduced the degree of degradation but did not entirely prevent all degradation from thermal charging: no loss of strength is observed, but an approximate $50 \%$ loss of RA is observed. This knowledge of HEE and the design considerations listed above have led to the successful use of alloy 718 in the hydrogen-fueled SSME.

Fabrication of the SSME requires considerable use of welds. Table II lists weld statistics for GTA welds for the SSME. Microfissures were an initial problem with the utilization of alloy 718. This was solved by a combination of metallurgical changes and improvements in welding technique. These changes included welding

Table II. GTA Weld Statistics for Alloy 718

\begin{tabular}{|c|c|c|c|}
\hline Weld Type & Product & Quality & Problems \\
\hline 3000 manual & $\begin{array}{l}300 \text { line } \\
(20 \% \text { alloy } 718)\end{array}$ & $\begin{array}{l}96 \% \text { effective } \\
\text { in liner weld }\end{array}$ & $40 \%$ lack of fusion \\
\hline \multirow[t]{3}{*}{1000 automatic } & $\begin{array}{l}300 \text { ducts } \\
(60 \% \text { alloy } 718)\end{array}$ & $\begin{array}{l}90 \% \text { with no } \\
\text { rework }\end{array}$ & $30 \%$ cracks \\
\hline & $\begin{array}{l}230 \text { robotic } \\
(80 \% \text { alloy } 718)\end{array}$ & & $20 \%$ porosity \\
\hline & $\begin{array}{l}620 \text { internal } \\
\text { (dissimilar metals) }\end{array}$ & & \\
\hline
\end{tabular}


in the $954^{\circ} \mathrm{C}$ solution heat-treated condition which provides a finer grain size that is less prone to microfissuring. Subsequent to welding, components are resolutioned at $1038^{\circ} \mathrm{C}$ to improve resistance to HEE. Also, EB welding at less than $25 \mathrm{~cm} / \mathrm{min}$ travel speed reduces thermal gradients, which results in a marked reduction in microfissuring. If circumstances do not permit a sufficiently slow travel speed during $E B$ welding, the weldment may be designed so the nailhead of the weld can be removed by machining. The nailhead contains the majority of the microfissures. Another technique involves the use of a subsequent, slow, EB wash pass to fuse all the microfissures in the nailhead. Currently, weld quality statistics show $96 \%$ effectiveness in linear inches of welds with $90 \%$ of the welds requiring no rework. The distribution of current weld problems (approximately) are $40 \%$ lack of fusion, $30 \%$ weld cracking, and $20 \%$ weld porosity.

\section{Summary}

In conclusion, the use of alloy 718 on the SSME has been highly successful. No failures have been attributed to this alloy in any of the component testing or under flight conditions. Large forgings, weighing up to 680 $\mathrm{kg}$, are routinely fabricated. Alloy 718 has been successfully brazed, and EB and GTA welded. The problems associated with microfissures during welding have been minimized by careful control of processing parameters and initial grain size. The HEE failures have been eliminated by control of microstructure, design considerations, and barrier coatings.

\section{References}

1. J. R. Lewis, “Materials and Processes for Shuttle's Main Engines," Metals Progress, March 1975, 41-51.

2. R. J. Walter, R. P. Jewett, and W. T. Chandler, "On the Mechanism of Hydrogen-Environment Embrittlement of Iron- and Nickel-base Alloys," Mat. Sci. and Eng, 5 (1969/70), 98-110.

3. L. G. Fritzemeier et al., "Hydrogen Embrittlement Research: A Rocketdyne Overview," Hydrogen Effects on Materials Behavior, ed. Neville R. Moody and Anthony W. Thompson (Warrendale, PA, The Metallurgical Society, 1990), 941-954. 